\title{
Population Dynamics and Feeding Behavior of Triatoma brasiliensis and Triatoma pseudomaculata, Main Vectors of Chagas Disease in Northeastern Brazil
}

\author{
Rodrigo Pedro Pinto Soares $/{ }^{+}$, Luciene das Graças Evangelista, \\ Luciano Soares Laranja*, Liléia Diotaiuti*
}

\begin{abstract}
Departamento de Parasitologia, Universidade Federal de Minas Gerais, Av. Antônio Carlos 6627, 31270-901
Belo Horizonte, MG, Brasil *Centro de Pesquisas René Rachou-Fiocruz, Av. Augusto de Lima 1715, 30190-002 Belo Horizonte, MG, Brasil
\end{abstract}

\begin{abstract}
Biological parameters of Triatoma brasiliensis and T. pseudomaculata that could influence the epidemiological importance of these insects as vectors of Trypanosoma cruzi were compared. The parameters studied were incubation period, interval between hatching or moulting and first feeding, number of blood meals, development time, mortality, net reproductive rate, instantaneous daily reproductive rate, time-lapse before starting feeding, duration of feeding, blood ingestion capacity, occurrence of defecation and blood ingestion velocity. Most aspects of feeding were similar for the two species, although $\mathrm{T}$. pseudomaculata had a longer life cycle than $\mathrm{T}$. brasiliensis producing one and two generations per year, respectively. The two species had similar instantaneous daily rates of population growth.
\end{abstract}

Key words: Triatoma brasiliensis - Triatoma pseudomaculata - population dynamics - feeding behavior - Brazil

Triatoma brasiliensis Neiva, 1911 and $T$. pseudomaculata Corrêa \& Espínola, 1964 are the most important vectors of Trypanosoma cruzi causative agent of Chagas disease - in the arid caatinga region of Northeastern Brazil. Both species occupy a range of domestic, peridomestic, and sylvatic ecotopes, with $T$. brasiliensis often associated with small rodents amongst rocky outcrops, and $T$. pseudomaculata more usually associated with birdnests and hollow trees (Forattini et al. 1981). Application of residual insecticides can eliminate domestic colonies of both species, but houses can then be reinvaded from the silvatic and peridomestic habitats. Our aim in this study, was to compare the two species in terms of various factors that could influence their epidemiological importance as domestic vectors of $T$. cruzi.

\section{MATERIALS AND METHODS}

Specimens of $T$. brasiliensis were collected from peridomestic habitats in the municipality of Simplício Mendes, State of Piauí, and specimens

\footnotetext{
This work was supported by CNPq, Centro de Pesquisas René Rachou-Fiocruz and benefited from additional support through the ECLAT network.

${ }^{+}$Corresponding author. Fax: + 55-31-295.3115. E-mail: rodrigo@cpqrr.fiocruz.br

Received 6 July 1999

Accepted 26 November 1999
}

of T. pseudomaculata were similarly collected in the municipality of Crateús, State of Ceará, Brazil. Eggs from the collected adults (40 from $T$. brasiliensis, 33 from T. pseudomaculata) were placed individually in small pots and observed daily until eclosion. The resulting nymphs were offered a daily feed on an anaesthetized mouse. Those that started feeding were allowed to engorge; those that did not start to feed within 30 min were left until the following day. Once bugs had taken a first blood meal, they were then offered a weekly feed. This regime (maintained at $24 \pm 2^{\circ} \mathrm{C} ; 56 \pm 6 \% \mathrm{rh}$ ) allowed us to establish the incubation period, the interval between hatching or moulting and the first feeding, the number of blood meals required by each instar, the development time, the net reproductive rate (Ro) and the instantaneous daily reproductive rate (r). In the case of 4 th and 5th instar nymphs and adults, we also noted the time-lapse before starting feeding, the duration of feeding and timing of defecation.

To determine bloodmeal intake, we used 30 bugs of each instar, weighed before and immediately after feeding. The blood meal intake ratios were calculated in relation to the body weight of each insect using the formula $(\mathrm{R}=(\mathrm{Wf}-\mathrm{Wi}) / \mathrm{Wi})$, where $\mathrm{Wf}$ is the weight after feeding $(\mathrm{mg})$ and $\mathrm{Wi}$ is the weight before feeding. Blood ingestion velocity was calculated by the formula $(\mathrm{V}=\mathrm{Wb} / \mathrm{T})$, where $\mathrm{Wb}$ is the ingested blood weight $(\mathrm{mg})$ and $\mathrm{T}$ is the interval time (minutes) between the beginning and the end of the feeding process. 


\section{RESULTS}

Population development - The mean number of eggs laid per female was 264 (range 37-385) for $T$. pseudomaculata and 142 (range 33-269) for $T$. brasiliensis. Egg viability was high for both species, with $100 \%$ successful eclosion in $T$. pseudomaculata and $92.5 \%$ in T. brasiliensis. Egg development was faster in T. pseudomaculata than in T. brasiliensis, but the duration of instar I to instar II was the similar for both species. Nymphal development during the subsequent instars was longer in T. pseudomaculata than in T. brasiliensis, resulting in an egg-to-adult life cycle of $212 \pm 21$ days for the former, and $160 \pm 14$ days for the latter (Table I). A partial life table analysis, following Southwood (1978), indicates a net reproductive rate (Ro) of 53.2 times per generation for T. brasiliensis and 120 times per generation for T. pseudomaculata under these conditions. The instantaneous daily reproductive rate $(r)$ was 0.010 for $T$. brasiliensis and 0.009 for T. pseudomaculata (Table IX).

Feeding and defecation - Most aspects of feeding behaviour were similar for the two species (Tables II-VIII) although nymphal instars of $T$. brasiliensis tended to be more aggressive than the adults in taking bloodmeals. No differences were apparent in time taken to initiate feeding, nor in the duration of feeding which increased by instar in both species. Some insects fed for more than 2 hr (Table V). T. brasiliensis instars I, III and V had more blood ingestion capacity than $T$. pseudomaculata. Nevertheless, no difference was observed for instars II and IV (Table VII). All $T$. brasiliensis instars were faster in obtaining blood meal from the host, except for the instar I $(\mathrm{p}=0.39)$ (Table VIII).

TABLE I

Life cycle of Triatoma brasiliensis and Triatoma pseudomaculata (days) under laboratory conditions $\left(24 \pm 2^{\circ} \mathrm{C} ; 56 \pm 6 \mathrm{rh}\right)$

\begin{tabular}{|c|c|c|c|c|c|c|c|}
\hline \multirow[t]{2}{*}{ Instar } & \multicolumn{3}{|c|}{ T. brasiliensis } & \multicolumn{3}{|c|}{ T. pseudomaculata } & \multirow[b]{2}{*}{$\mathrm{p}$ value } \\
\hline & Min. & Max. & Mean \pm SD & Min. & Max. & Mean \pm SD & \\
\hline Egg - I & 23 & 27 & $25 \pm 1$ & 17 & 22 & $19 \pm 1$ & 0.00 \\
\hline I - II & 15 & 45 & $23 \pm 7$ & 15 & 49 & $25 \pm 8$ & 0.37 \\
\hline II - III & 14 & 48 & $24 \pm 5$ & 24 & 42 & $33 \pm 5$ & 0.00 \\
\hline III - IV & 14 & 35 & $23 \pm 5$ & 35 & 64 & $48 \pm 7$ & 0.00 \\
\hline IV - V & 18 & 41 & $27 \pm 5$ & 19 & 82 & $52 \pm 15$ & 0.00 \\
\hline V - Adult & 33 & 64 & $44 \pm 8$ & 36 & 124 & $55 \pm 17$ & 0.00 \\
\hline Total & 117 & 260 & $160 \pm 14$ & 146 & 383 & $212 \pm 21$ & 0.00 \\
\hline
\end{tabular}

TABLE II

Interval between hatching or moulting and the first feeding (days)

\begin{tabular}{|c|c|c|c|c|c|c|c|}
\hline \multirow[t]{2}{*}{ Instar } & \multicolumn{3}{|c|}{ Triatoma brasiliensis } & \multicolumn{3}{|c|}{ Triatoma pseudomaculata } & \multirow[b]{2}{*}{$\mathrm{p}$ value } \\
\hline & Min. & Max. & Median & Min. & Max. & Median & \\
\hline I & 2 & 12 & 4 & 1 & 6 & 3 & 0.00 \\
\hline II & 0 & 17 & 4 & 1 & 5 & 2 & 0.00 \\
\hline III & 0 & 12 & 2 & 1 & 9 & 3 & 0.54 \\
\hline IV & 1 & 20 & 2 & 3 & 9 & 5 & 0.03 \\
\hline V & 0 & 14 & 3 & 3 & 31 & 10 & 0.00 \\
\hline Adult & 1 & 23 & 6 & 5 & 35 & 25 & 0.00 \\
\hline
\end{tabular}

TABLE III

Number of blood meals of Triatoma brasiliensis and Triatoma pseudomaculata nymphal instars

\begin{tabular}{|c|c|c|c|c|c|c|c|}
\hline \multirow[t]{2}{*}{ Instar } & \multicolumn{3}{|c|}{ T. brasiliensis } & \multicolumn{3}{|c|}{ T. pseudomaculata } & \multirow[b]{2}{*}{$\mathrm{p}$ value } \\
\hline & Min. & Max. & Median & Min. & Max. & Median & \\
\hline I & 1 & 5 & 3 & 1 & 6 & 3 & 0.34 \\
\hline II & 1 & 4 & 2 & 2 & 6 & 4 & 0.00 \\
\hline III & 1 & 3 & 2 & 3 & 6 & 5 & 0.00 \\
\hline IV & 1 & 3 & 2 & 1 & 6 & 4 & 0.00 \\
\hline $\mathrm{V}$ & 1 & 4 & 2 & 1 & 3 & 2 & 0.44 \\
\hline Total & 1 & 5 & 2 & 1 & 6 & 3 & 0.00 \\
\hline
\end{tabular}


TABLE IV

Time-lapse before starting feeding (min:sec) according to the instar for Triatoma brasiliensis and Triatoma pseudomaculata

\begin{tabular}{|c|c|c|c|c|c|c|c|}
\hline \multirow[t]{2}{*}{ Instar } & \multicolumn{3}{|c|}{ T. brasiliensis } & \multicolumn{3}{|c|}{ T. pseudomaculata } & \multirow[b]{2}{*}{$\mathrm{p}$ value } \\
\hline & Min. & Max. & Average \pm s.d. & Min. & Max. & Average \pm s.d. & \\
\hline I & 00:00 & $11: 28$ & $03: 45 \pm 03: 15$ & $00: 18$ & $24: 00$ & $03: 41 \pm 03: 56$ & 0.90 \\
\hline II & 00:05 & $12: 54$ & $02: 54 \pm 02: 57$ & 00:05 & $20: 20$ & $03: 51 \pm 03: 47$ & 0.05 \\
\hline III & $00: 12$ & $11: 59$ & $03: 34 \pm 03: 05$ & $00: 10$ & $27: 00$ & $04: 43 \pm 05: 14$ & 0.06 \\
\hline IV & $00: 13$ & $15: 20$ & $03: 30 \pm 03: 42$ & $00: 42$ & 29:06 & $06: 18 \pm 05: 08$ & 0.00 \\
\hline $\mathrm{V}$ & $00: 20$ & $13: 11$ & $03: 59 \pm 03: 36$ & 00:00 & $12: 50$ & $04: 20 \pm 03: 30$ & 0.60 \\
\hline Adult & $01: 10$ & $12: 59$ & $06: 09 \pm 03: 21$ & 00:19 & $14: 00$ & $05: 28 \pm 03: 54$ & 0.41 \\
\hline
\end{tabular}

TABLE V

Time of feeding (hr:min:sec) according to the instar for Triatoma brasiliensis and Triatoma pseudomaculata

\begin{tabular}{|c|c|c|c|c|c|c|c|}
\hline \multirow[t]{2}{*}{ Instar } & \multicolumn{3}{|c|}{ T. brasiliensis } & \multicolumn{3}{|c|}{ T. pseudomaculata } & \multirow[b]{2}{*}{$\mathrm{p}$ value } \\
\hline & Min. & Max. & Average \pm s.d. & Min. & Max. & Average \pm s.d. & \\
\hline I & $01: 55$ & 01:20:51 & $23: 25 \pm 16: 45$ & $01: 49$ & 02:09:47 & $18: 17 \pm 15: 55$ & 0.05 \\
\hline II & $01: 50$ & 01:31:57 & $22: 11 \pm 17: 39$ & 03:19 & 01:10:38 & $19: 49 \pm 11: 55$ & 0.30 \\
\hline III & 03:08 & 03:10:40 & $29: 19 \pm 28: 40$ & $01: 20$ & 01:18:36 & $23: 37 \pm 14: 20$ & 0.13 \\
\hline IV & $03: 36$ & $02: 52: 37$ & $32: 16 \pm 29: 22$ & $02: 12$ & 01:08:28 & $29: 18 \pm 15: 47$ & 0.44 \\
\hline V & 03:37 & 02:09:40 & $42: 00 \pm 28: 37$ & $03: 22$ & 02:09:32 & $50: 33 \pm 26: 48$ & 0.10 \\
\hline Adult & $08: 49$ & 01:26:47 & $28: 40 \pm 19: 04$ & 04:03 & 00:58:35 & $27: 25 \pm 12: 52$ & 0.74 \\
\hline
\end{tabular}

TABLE VI

Occurrence of defecation during and immediately after feeding of IV, V instars and adults of Triatoma brasiliensis and Triatoma pseudomaculata

\begin{tabular}{lccr}
\hline Instar & T. brasiliensis & T. pseudomaculata & p value \\
\hline IV & $50 \%$ & $75 \%$ & 0.00 \\
V & $66 \%$ & $86 \%$ & 0.00 \\
Adult & $56 \%$ & $50 \%$ & 0.47 \\
\hline
\end{tabular}

\section{TABLE VII}

Blood ingestion capacity of the nymphal instars of Triatoma brasiliensis and Triatoma pseudomaculata

\begin{tabular}{lccc}
\hline Instar & T. brasiliensis & T. pseudomaculata & $\mathrm{p}$ value \\
\hline I & 5.16 & 4.07 & 0.00 \\
II & 3.57 & 3.04 & 0.00 \\
III & 4.06 & 3.32 & 0.00 \\
IV & 4.92 & 4.42 & 0.00 \\
V & 5.35 & 4.32 & 0.00 \\
\hline
\end{tabular}

\section{TABLE VIII}

Blood ingestion velocity ( $\mathrm{mg} / \mathrm{min})$ of Triatoma brasiliensis and Triatoma pseudomaculata nymphal instars in contact with anaesthetized mouse

\begin{tabular}{lccc}
\hline Instar & T. brasiliensis & T. pseudomaculata & p value \\
\hline I & $0.32 \pm 0.14$ & $0.37 \pm 0.18$ & 0.39 \\
II & $1.04 \pm 0.71$ & $0.36 \pm 0.19$ & 0.00 \\
III & $1.90 \pm 1.02$ & $0.98 \pm 0.49$ & 0.00 \\
IV & $4.25 \pm 2.01$ & $1.43 \pm 0.61$ & 0.00 \\
V & $6.33 \pm 3.19$ & $2.77 \pm 1.45$ & 0.00 \\
\hline
\end{tabular}

TABLE IX

Partial instar specific life table for Triatoma brasiliensis (T.b.) and Triatoma pseudomaculata (T.p.) (notation follows Southwood 1978)

\begin{tabular}{llllcr}
\hline & \multicolumn{2}{c}{ T. brasiliensis } & & \multicolumn{2}{c}{ T. pseudomaculata } \\
\cline { 2 - 3 } \cline { 6 - 6 } Instar & $\mathrm{lx}$ & $\mathrm{dx}$ & & $\mathrm{lx}$ & $\mathrm{dx}$ \\
\hline Egg & 40 & 3 & & 33 & 0 \\
I & 37 & 1 & & 33 & 0 \\
II & 36 & 2 & & 33 & 1 \\
III & 34 & 0 & & 32 & 1 \\
IV & 34 & 0 & & 31 & 0 \\
V & 34 & 0 & & 31 & 1 \\
Adult & 34 & 34 & & 30 & 30 \\
\hline
\end{tabular}

number of females produced

by cohort $\mathrm{x}$ mean eggs Ro $=\frac{\text { laid per female }}{\begin{array}{c}\text { number of eggs } \\ \text { beginning cohort }\end{array}}=53.3$ (T.b.) and 120.0 (T.p.)

$\mathrm{r}=\log (\mathrm{Ro}) /$ egg-to-egg generation time $=0.010(T$. brasiliensis) and 0.009 (T. pseudomaculata); 1x: number entering instar $\mathrm{x}$; $\mathrm{dx}$ : number dying in instar $\mathrm{x}$.

Defecation during and immediately after feeding occurred in $75 \%, 86 \%$ and $56 \%$ of instars IV, $\mathrm{V}$ and adults of $T$. pseudomaculata. For $T$. brasiliensis the results were $50 \%, 66 \%$ and $50 \%$, respectively (Table VI). Statistical analysis revealed that $T$. pseudomaculata instars IV and V released feces more frequently than $T$. brasiliensis instars. No difference was observed for adults. 


\section{DISCUSSION}

Epidemiological studies indicate that $T$. pseudomaculata is less efficient than T. brasiliensis as a vector of T. cruzi. Where both species occur, T. brasiliensis tends to predominate in domestic habitats, with $T$. pseudomaculata more usually encountered in peridomestic habitats such as chicken coops (Alencar 1987). However, high levels of intradomiciliary colonization by $T$. pseudomaculata have been observed in the municipality of Sobral, Ceará (Souza et al. 1999), although a survey of 103 houses infested with this species, showed only two people to be seropositive for $T$. cruzi infection - indicating a virtual absence of vector-borne transmission (Frota et al. 1999). This contrasts with similar studies of areas infested primarily with $T$. brasiliensis, for example in the municipality of Independência, Ceará, where studies by our group show a human seroprevalence of $5.7 \%$ infection with $T$. cruzi (Diotaiuti et al. 1998).

T. brasiliensis tends to be an aggressive feeder in the field, sometimes attacking people even during the day. Under our experimental conditions however, the aggressiveness of both species was similar. Both species tended to feed for long periods if undisturbed, with some bugs feeding for more than $2 \mathrm{~h}$. However, we noted that $T$. pseudomaculata was readily disturbed from feeding by even slight movements of the mouse, whereas $T$. brasiliensis continued to feed even when the mouse made several unconscious movements. Both species defecated frequently while feeding, and T. pseudomaculata instars IV and V defecated more often than the same instars of $T$. brasiliensis. No such difference was observed for adults. Although the transmission of T. cruzi is crucially dependent on the releasing of feces over the host, the factors involved are complex. Trumper and Gorla (1991) reported that in T. infestans defecation depends on the quantity of blood ingested and on the starvation period. Diotaiuti et al. (1995) showed for T. infestans and T. sordida the occurrence of defecation during and/or immediately after feeding in $90 \%$ and $86 \%$ of the insects, respectively, compared with our observations of $50 \%$ in T. brasiliensis and $75 \%$ in T. pseudomaculata. Nevertheless, we suspect that the ready disturbance of T. pseudomaculata could influence its likelihood of completing a feed and defecating on its host. During its development, T. brasiliensis also ingested more blood than T. pseudomaculata, which, in nature, could increase its likelihood of taking an infective blood meal since there seems to be a positive correlation between blood ingestion capacity and the subsequent infection rate by $T$. cruzi (Minter et al. 1978, Mello \& Chiarini 1980).
The blood ingestion velocity ( $\mathrm{mg} / \mathrm{min}$ ) was the same for instar I of both species, but for the subsequent nymphal instars it was faster in $T$. brasiliensis, suggesting that $T$. brasiliensis is more efficient than T. pseudomaculata in obtaining a blood meal. This was reflected in the different development rates of the two species. T. brasiliensis developed faster from egg to adult ( $160 \pm 14$ days) than T. pseudomaculata ( $212 \pm 21$ days), suggesting that the former would be likely to complete two generations per year, while the latter would be less likely to do so. There were no differences in egg viability, although the incubation period was faster in T. pseudomaculata. For both species the duration from instar I to II was similar, but subsequent development was slower for $T$. pseudomaculata. Similar results of egg-incubation for T. pseudomaculata were observed by Gonçalves et al. (1997), but for the subsequent instars, our results showed a faster life cycle than that observed by these authors. Several factors may influence these differences, including the length of time adapted to the laboratory, since our observations were made on the offspring of field-collected insects. In addition, our insects were fed on mouse, while those of Gonçalves et al. (1997) were fed on bird (Columba livia). Diotaiuti and Dias (1987) demonstrated that Rhodnius neglectus fed on mouse had a shorter development period compared to those fed on bird. Although T. pseudomaculata seems associated with birds in its natural ecotopes (Forattini et al. 1981), its developmental time seems to be faster when feeding on mouse. The interval between hatching or moulting and the first subsequent feed was shorter for T. brasiliensis, and in general, the number of blood meals before moulting was higher for T. pseudomaculata which sometimes required up to six bloodmeals. For both species, even instar I required more than one feed before moulting, whereas published studies generally show that only a single meal is taken by 1 st instars of other species such as $R$. prolixus (Rabinovich et al. 1979), Panstrongylus megistus, T. infestans and T. sordida (PerlowagoraSzumlewics 1975).

There were considerable differences in fecundity between the two species, resulting in marked differences in the net reproductive rates of 53.3 for T. brasiliensis, and 120 for T. pseudomaculata. Because of converse differences in the generation time however, the instantaneous daily rates of population growth were similar, at 0.010 for $T$. brasiliensis and 0.009 for T. pseudomaculata. These rates are similar to those calculated for $T$. infestans and R. prolixus (Rabinovich 1972a,b, 1974) under broadly similar laboratory conditions. However the different rates would appear to re- 
flect different environmental adaptations of the two species, in the sense that the greater innate fecundity of T. pseudomaculata may indicate that in nature it may be exposed to higher risk to nymphal survival.

\section{REFERENCES}

Alencar JE 1987. Historia Natural da Doença de Chagas no Estado do Ceará, Imprensa Universitária da UFC, Fortaleza, $341 \mathrm{pp}$.

Diotaiuti L, Dias JCP 1987. Estudo comparativo do ciclo evolutivo de Rhodnius neglectus alimentados em pombos ou camundongos. Rev Soc Bras Med Trop 20: 95-100.

Diotaiuti L, Borges EC, Lorosa ES, Andrade RE, Carneiro FFC, Faria Filho OF, Schofield CJ 1998. Current transmission of Chagas disease in the state of Ceara, Brazil. Mem Inst Oswaldo Cruz 93 (Suppl. II): $65-66$

Diotaiuti L, Penido CMP, Pires HHR, Dias JCP 1995. Dinâmica da alimentação e dejeção do Triatoma sordida. Rev Soc Bras Med Trop 28: 195-198.

Forattini OP, Barata JMS, Santos JLF, Silveira AC 1981. Hábitos alimentares, infecção natural e distribuição de triatomíneos domiciliados na região nordeste do Brasil. Rev Saúde Públ 15: 113-164.

Frota FCC, Lima JWO, Braga VSS 1999. Infecção humana pelo Trypanosoma cruzi, num foco urbano de Triatoma pseudomaculata, na cidade de Sobral, norte do Ceará. Rev Soc Bras Med Trop 32 (Suppl. I): $85-86$.

Gonçalves TCM, Cunha V, Oliveira E, Jurberg J 1997. Alguns aspectos da biologia de Triatoma pseudomaculata Corrêa \& Espínola, 1964, em condições de laboratório (Hemiptera: Reduviidae: Triatominae). Mem Inst Oswaldo Cruz 92: 275-280.

Mello DA, Chiarini C 1980. Susceptibilidade dos diferentes estádios evolutivos de Triatoma sordida Stal, 1859 e de Rhodnius neglectus Lent, 1954 à infecção pelo Trypanosoma cruzi. Rev Bras Biol 40: 327-334.

Minter DM, Minter-Goedibloed E, Marshall TFC 1978. Comparative xenodiagnosis with three triatomine species of different hosts with natural and experimental chronic infections with Trypanosoma cruzi. Trans R Soc Trop Med Hyg 72: 84-91.

Perlowagora-Szumlewics A 1975 . Laboratory colonies of Triatominae, biology and population dynamics. In New Approaches in American Trypanosomiasis Research. PAHO/WHO Sci Publ 318: 63-82.

Rabinovich JE 1972a. Vital statistics of Triatominae (Hemiptera: Reduviidae) under laboratory conditions. I. Triatoma infestans Klug. J Med Entomol 9: 351-370.

Rabinovich JE 1972b. Vital statistics of Triatominae (Hemiptera: Reduviidae) under laboratory conditions. II. Rhodnius prolixus, Stål. Abstracts of the 14th International Congress of Entomology, Canberra, p. 291.

Rabinovich JE 1974. Demographic strategies in animal populations: a regression analysis. In FB Golloy \& E Medina (eds), Tropical Ecological Systems, Springer Verlag, New York, p. 19-40.

Rabinovich JE, Leal JA, Piñero DF 1979. Domiciliary biting frequency and blood ingestion of the Chagas disease vector Rhodnius prolixus, Stål (Hemiptera: Reduviidae), in Venezuela. Trans $R$ Soc Trop Med Hyg 73: 272-283.

Souza LC, Frota FCC, Souza JA, Zuza CAS, Lima JWO 1999. Descrição de um foco urbano de Triatoma pseudomaculata (Hemiptera: Reduviidae: Triatominae) na cidade de Sobral, norte do Ceará. Resultados preliminares. Rev Soc Bras Med Trop 32 (Suppl. I): 84-85.

Southwood TRE 1978. Ecological Methods, 2nd ed., Chapman \& Hall, London, 524 pp.

Trumper EV, Gorla DE 1991. Density-dependent timing of defaecation by Triatoma infestans. Trans $R$ Soc Trop Med Hyg 85: 800-802. 